\title{
Grape pruning methods can affect Botrytis bunch rot
}

\author{
PhilA. Phillips J John H. Foott $\square$ Lizanne Righetti
}

The vineyard training/pruning system can dramatically influence the amount of Botrytis bunch rot. Trying to achieve better light reception can impede air movement and result in greater incidence of rot.

Researchers recently concluded that growers can manage a vine's microclimate to reduce the development of Botrytis bunch rot in vineyards by increasing the air movement around clusters. Differences in Botrytis severity were further noted during a study of different trellis heights and different training and pruning methods in a Santa Maria white riesling vineyard.

TABLE 1. Comparison of three training techniques for grapevine*

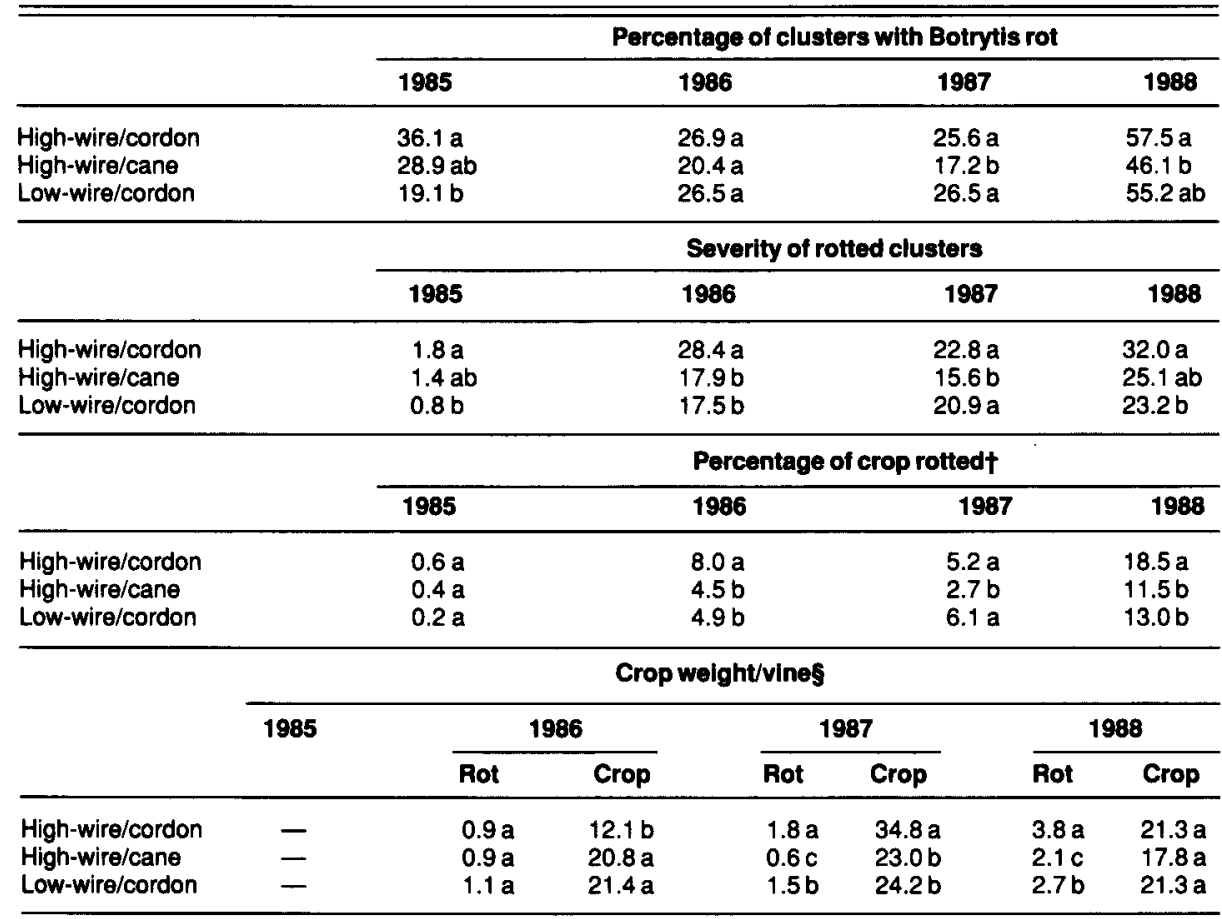

-Duncan's multiple range test for statistical means separation. Figures not showing a common letter are significantly different from one another at the $5 \%$ error level.

tTotal percentage rotted for all rotted clusters divided by total number of clusters.

\&Pounds per vine
Previous data had focused on vine yield and fruit composition parameters. In 1985 the study was expanded to include the incidence of Botrytis bunch rot among the differently established vines.

\section{Methods}

The trial, established in 1982, consisted of three treatments (fig. 1): a low spur-pruned bilateral cordon at 36 inches with two kicker canes wrapped onto a wire 46 inches high; a high-cordon at 55 inches with no upper foliage support wires; and a high, headtrained, cane-pruned treatment at 55 inches, also without any additional upper wire. Treatments were replicated five times using five-vine plots in a completely randomized design.

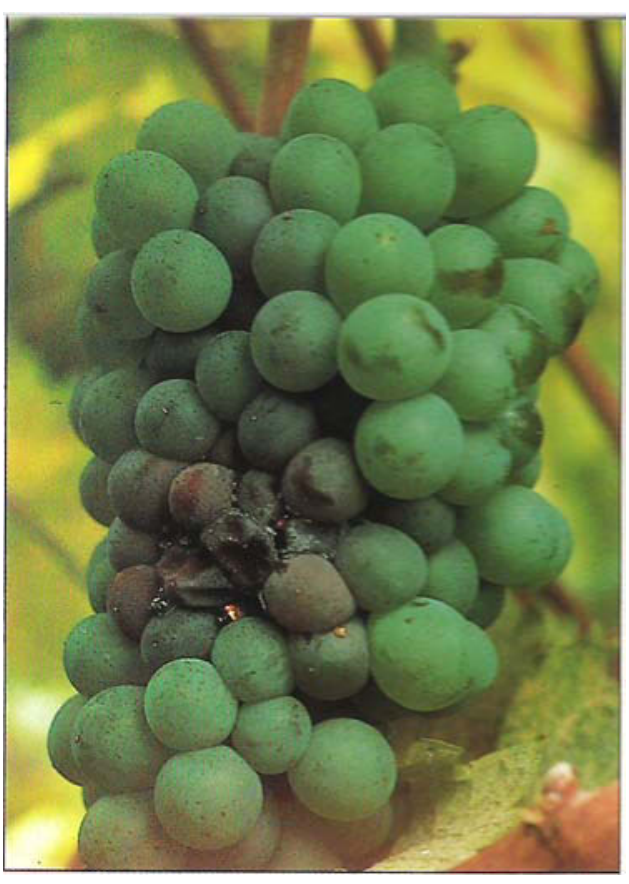

Insufficient air circulation can promote Botrytis bunch rot in grapes. Proper pruning keeps the fruit bunches clear of enveloping leaves.
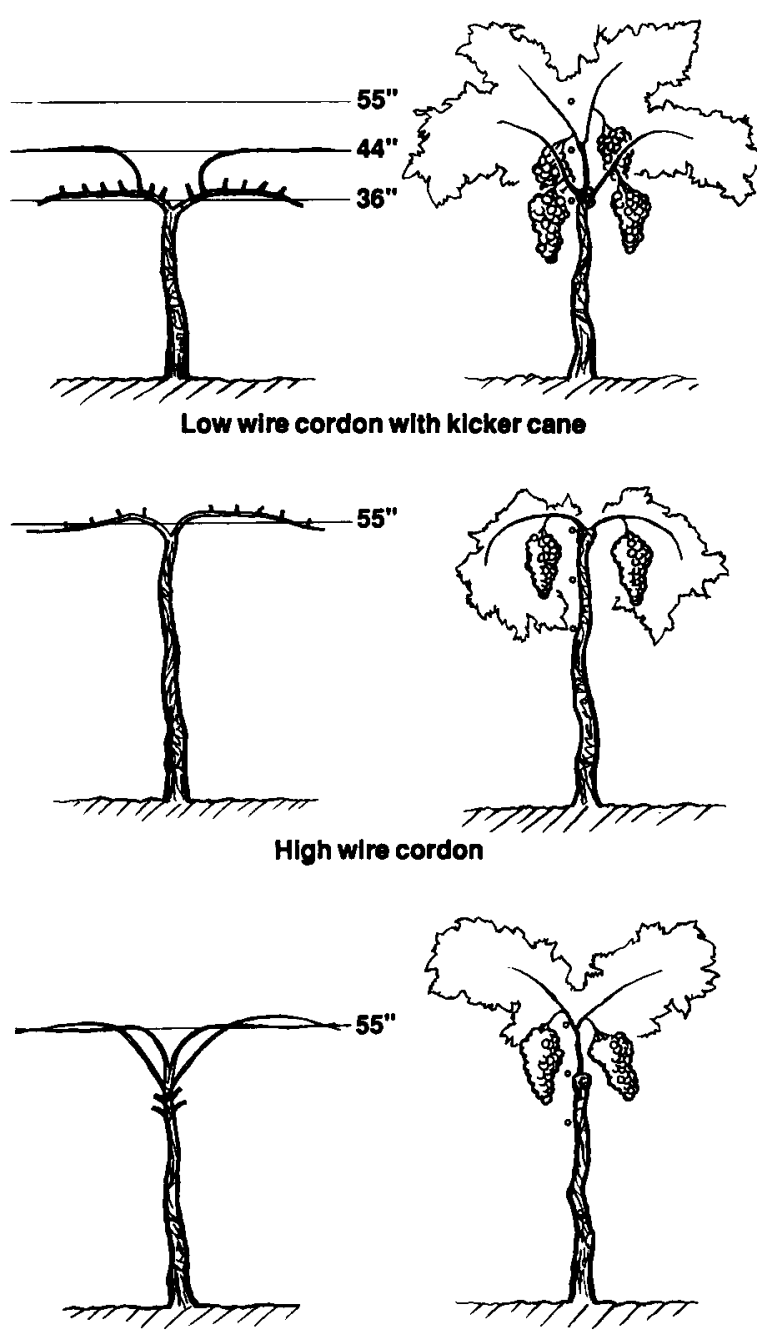

High wire cane

Fig. 1. Three training/pruning alternatives for grapevine (left: pruned vine on trellis; right: cross-section of bearing vine). 
Each winter from 1982 through 1988, every vine was pruned to 70 buds. During the harvests of 1985-88, we scored the three middle vines of each five-vine plot for rot percentage and severity. Each cluster was harvested and individually assessed for presence or absence of rot, and the rot percentage was determined for each rotted cluster. Finally, harvest weights were taken for each plot in 1986, 1987, and 1988 to determine the percentage rot of the crop by weight.

\section{Results}

It was hypothesized that the 55-inch vine training systems would place the vine canopy higher into the prevailing wind, resulting in better air mixing, less humidity, and less Botrytis bunch rot. However, the vines trained as high-wire cordons generally had significantly more rot than either the highwire cane or low-wire cordon systems.

Rot severity was significantly greater in the high-wire cordon vines than in the highwire cane vines for 2 out of 4 years, and significantly greater than the low-wire vines for 3 out of 4 years (table 1). In most years, the high-wire cane system tended to have fewer rotted clusters, although only in 1987 was the difference significant.

In cross-section (fig. 1), you can see that a vine grown on the high-wire cordon system places the clusters in the middle of an enveloping canopy of foliage. In contrast, the clusters of vines grown on the high-wire cane and low-wire cordon systems actually fall away from and below most of the foliage, theoretically allowing better air movement around the clusters.

\section{Conclusions}

Attempts to increase sunlight penetration by growing grapevines on a high-wire, bilateral cordon, spur-pruned system actually harmed the crop by increasing the incidence of Botrytis bunch rot. Based on these results, a high-wire system should only be used either in conjunction with cane pruning or, possibly, with an additional foliage catch wire that will prevent the development of an enveloping foliage canopy that could foster Botrytis bunch rot.

\section{Acknowledgements}

The authors gratefully acknowledge the assistance and cooperation of Sierra Madre Vineyards, Dale Hampton, and Lon Fletcher.

Phil A. Phillips is IPM Advisor for the South] Central Coast area; John H. Foott is Farm Advisor in San Luis Obispo County; and Lizanne Righetti is Cooperative Extension Field Assistant, San Luis Obispo County.

\title{
Water quality and subsurface soil variabilities affect infiltration
}

\author{
Jan W. Hopmans $\square$ Jim Maclntyre $\square$ Randal J.Southard
}

\section{Variations in the soil's chemical or physical structure may affect its ability to absorb water. By adding sodium to irrigation water, re- searchers decreased infiltration during subsequent irrigations. In addition, the thickness and charac- ter of soil layers may obscure infiltration effects of tillage and water quality.}

Poor water penetration affects crop production on over 2.5 million acres of irrigated land in California. Generally, infiltration rates decrease substantially after a firstirrigation. Farmers commonly cultivate after each irrigation to break up the soil, but during the growing season they cannot-such a practice could destroy the crop. Given that infiltration rates are low, the only way to increase cumulative infiltration is to increase the intake time, thereby letting the water infiltrate longer. For furrow irrigation, the most widely used method in California, longer infiltrations are achieved by increasing the set time. This can lead to the loss of large volumes of water to runoff.

Many studies have shown that growers can improve infiltration rates by incorporating various calcium compounds, such as gypsum, lime, and calcium-nitrates, into the soil surface or into the irrigation water. But other studies looking into beneficial effects on infiltration from specific tillage and crop-rotation practices have been inconclusive.

These practices are expected to change the chemistry or structure of the soil surface. However, differences in soil properties below the surface may obscure differences in infiltration caused by soil surface effects.

The objectives of our study were twofold. First, we investigated whether adding sodium to water in an early irrigation would decrease infiltration during a subsequent irrigation. Second, we considered the possibility that differences in infiltration between treatments could be explained partly by variable soil characteristics.

\section{Field experiment}

The field study site was the Campbell Tract, a research facility of the University of Cali- fornia at Davis. The sampling sites were in Yolo loam and Yolo silty clay loam. Infiltration was measured with 4-by 4-foot-square infiltrometers $0.3 \mathrm{~m}$ ( 1 foot) deep.

Infiltration was continuously measured for 8 to 10 hours through registration of the water level in a storage tank by a pen chart recorder. The rate of change of infiltration as recorded on the charts was converted to actual infiltration rates in centimeters per day ( 1 inch/day is about $2.5 \mathrm{~cm} /$ day).

Each infiltration experiment consisted of two wettings. The first was either with highquality water (electrical conductivity $[E C]=$ $0.3 \mathrm{mmho} / \mathrm{cm}$, sodium adsorption ratio [SAR] $<0.1$ ), or with sodium-added water $(E C=2.6 \mathrm{mmho} / \mathrm{cm}, \mathrm{SAR}=8.4)$. Electrical conductivity increases in a linear fashion with an increasing amount of salts, whereas SAR is an index for the amount of sodium ions in the soil water. For both treatments, this first wetting was followed by deionized water applied 4 to 6 weeks later during a second wetting. Each treatment was replicated four times.

The effect of water quality on infiltration was tested at two locations 330 feet apart in the same field (referred to as WEST and EAST). We measured infiltration rate from 16 infiltrometers, 8 at the western and 8 at the eastern location.

Water content changes with depth were monitored with a neutron probe during and after each infiltration test. The water content measurements gave us an independent measure of the total amount of water infiltrated and indicated the position of the wetting front during the infiltration tests. The following soil surface properties were measured before the first wetting: electrical conductivity of saturation paste EC (mmho/cm); $\mathrm{pH}$; percentages of sand, silt, and clay; cation exchange capacity (CEC); and extractable sodium, potassium, magnesium, and calcium (all in meq/100 g dry soil). The EC and extractable cations were also determined after the first and second wettings.

\section{Analysis of tests}

Infiltration rates are characterized as a function of time to $t=0.35$ days for each of the infiltration tests (fig. 1). We measured eight infiltration curves: four replicates for each of the first and second wettings. For some 